\title{
Practical Interventions to Improve Domain-Specific Social, Emotional, or Academic \\ Outcomes for Twice-Exceptional Individuals (2e)
}

\author{
La Shun L. Carroll \\ University at Buffalo Graduate School of Education \\ lcarroll@buffalo.edu \\ ORCID — https://orcid.org/0000-0003-4132-6392
}

\begin{abstract}
What began nearly a century ago with the contributions of Hollingworth and Asperger, among others, has developed into a field dedicated to the study of gifted individuals with a disability. These twice-exceptional (2e) people and their unique set of needs differ from those of their onceexceptional counterparts on either end of the spectrum and often remain unaddressed or are discovered very late in life resulting in longterm consequences. For those discovered, effective treatment options to improve their quality of life remain uncertain. The goal of the present paper was to determine whether effective interventions exist to improve domain-specific (i.e., social, emotional, or academic) outcomes for people exhibiting both signs of giftedness and disability. A query was performed using evidence databases TRIP and PDQ in addition to University at Buffalo Libraries holdings for "twice-exceptional," "Giftedness," "Disability," and "intervention." The hits were reduced to the four most relevant, freely available studies in English that were selected for critique. Despite the selected studies being found to share methodological similarities that were their strengths and conducive to comparison, they also had threats to validity that served as potential weakness. Not only can directly effective interventions improve specific domains for $2 \mathrm{e}$ individuals, but the effects of domain-specific interventions may carry over into another domain resulting in indirect effects.
\end{abstract}


Keywords: Twice-Exceptional, Interventions, Gifted, Disability 


\section{Practical Interventions to Improve Domain-Specific Social, Emotional, or Academic Outcomes for Twice-Exceptional Individuals}

\section{Background \& Introduction}

The focus on twice-exceptionality began nearly 100 years ago in the early $20^{\text {th }}$ century (Subotnik, Olszewski-Kubilius, \& Worrell, 2011). Since its beginnings, there have always been skeptics who refuse to acknowledge the simultaneous coexistence of gifts or talents with disabilities or deficits is possible despite published positions and the emerging literature (Reis, Baum, \& Burke, 2014). The most cogent arguments against twice-exceptionality (2e) relate to the absence of any universally agreed-upon criteria comprising a consensus for an accepted definition. Although difficulty may exist in establishing consensus for a definition of twiceexceptionality (2e) - even by those who claim it - the confusion concerning a definition is not necessarily indicative of confusion regarding what is referred to as twice-exceptionality.

To clarify the notion, a twice-exceptional Community of Practice $(2 \mathrm{e} \mathrm{CoP})$ convened and developed a definition. It is not disputed that individuals who are twice-exceptional (2e) are those who are "both gifted and have learning, emotional, behavioral, or social issue" (Summit Center, n.d.). In light of these characteristics and their consequences, the definition of twiceexceptionality ultimately drafted by the $2 \mathrm{e} \mathrm{CoP}$ focused on the identification, enrichment, and establishment of support systems because of higher risk for personal, or academic difficulties (Reis, Baum, \& Burke, 2014). The higher risk for these 2e individuals stems from the presence of comorbid diagnoses that may obscure one another, which makes them extremely vulnerable yet challenging to identify because existing methods are not effective in doing so (Reis, Baum, \& Burke, 2014). Identification is critical if 2e individuals are to receive strategies, techniques, or other interventions that are appropriate for their particular situation. 


\section{Formulating the PICO Question}

With a goal of facilitating the early identification and referral for appropriate intervention for $2 \mathrm{e}$ children, the following was developed as the research question guiding this paper: "For gifted individuals with a disability (i.e., "twice-exceptional”) do effective interventions/strategies exist to improve domain-specific (i.e., social, emotional, or academic) outcomes?" As an aside, for a subsequent research paper, I contemplated doing an exploratory analysis into the following question: "If effective interventions do exist, then is it possible any of these effective domainspecific interventions can successfully transfer to other domains." In other words, for example, I wondered "if social interventions exist, then would any of these social interventions carry over to the emotional realm as beneficial?" Tentatively, I hypothesize they would, but have yet to fully endeavor and am unable to claim anything with certainty presently.

The main research question is referred to as being "foreground" in essence. As a foreground question, it asks for specific knowledge that aims to both guide and inform clinical decision-making (Fineout-Overholt \& Johnston 2005). Given the function of a foreground question, its domain may best be described as broadly therapeutic.

Broadly therapeutic is used in reference to the domain of therapy, which encompasses two domains itself: both therapy and prevention (University of Canberra, 2018). Questions concerning therapy inquire about the effectiveness of an intervention in improving outcomes. Nonetheless, questions of prevention relate to inquiries about the potential for an intervention to stop morbidity and mortality. Since the ability of an intervention to prevent morbidity or mortality may be considered an improvement of outcome from any perspective, questions of prevention would justifiably fall under the domain of therapy. 
Although various ways to describe the following word exist, for the present paper, "intervention" is to be understood as some form of action, strategy, technique, therapy, or procedure that supplements an individual's current educational activities in the curriculum. As a strategy, an intervention is "used to teach a new skill, build fluency in a skill, or encourage ... an existing skill to new situations or settings" (Wright, 2010). That is, to say, I view the intervention as an addition to something, above and beyond, but not necessarily as a replacement of anything that may be currently done. Intervention as something to which one is exposed should not detract from ongoing efforts.

To research the topic, the tools used included evidence databases such as TRIP or PDQ$\mathrm{DB}$, in addition to UB libraries through remote web access. Of the hits returned after searching for "twice-exceptional," "2e", "Giftedness," "Disability," and "intervention," those selected for inclusion were had to concern effective interventions, and either had been primary research designed as Randomized Control Trials (RCT) or Observational Studies. Also, inclusion was limited to papers in the English language that were free to access. The four studies selected were reviewed and the pertinent information used for analysis was recorded in review tables labelled Tables 1 through 4 that have been included. Based on the review tables, the studies were compared and contrasted with the results and conclusions comprising the next section of this paper.

\section{Critique}

Upon comparing and contrasting the four main studies, there were both methodological strengths and weaknesses found. These strengths and weaknesses potentially limit the generalizability of the results or findings. The studies shared similarities, which were found to be 
in the consistency of their strengths whereas weaknesses were what discerned them from one another.

\section{Similarities Among the Methodological Strengths}

Among the strengths shared by the studies, it was operationalizing high IQ, establishing a reasonable criterion, and the use of comparison groups in Antshel et al. (2007) that stood out. The study by Antshel et al. (2007) showed the strength that was consistent with Tao \& Shi's (2018) implementation of multiple verification processes in the study. Also, the use of a multidisciplinary team to diagnose participants in Pisacco et al. (2018) aligned with the previous two studies. Consistent with the studies as mentioned above, Foley-Nicpon et al. (2017) decided to conduct their research during an established 2-week long summer program. Their choice to evaluate participants before, at the end of, and three months after the intervention along with the use of validated instruments/measurement devices (i.e., PALS \& FQS) helped to solidify the consistency found among the strengths through the use of independent measurements.

By independent, it is meant that the observations and findings of the primary studies considered have occurred separated by either "occasion," "instrument," or "person" inclusively. Occasion conveys the temporal aspect of an observation in its referent encompassing "when" the observed events took place. Instrument refers to the "with what" and "how" the observation was made and recorded. Finally, person represents the individual by whom the observations and findings are made. As these are all dimensions or perspectives on observations that occur and are made during research, the consistency among the studies will allow for comparisons and contrasts to be made between them meaningfully.

Whether made between contemporary studies, or those of the past or future, successful comparisons and contrasts require some level of agreement between that which is compared. 
That is, to say, for useful comparison and contrast to be possible, there needs to be a minimum level of consistency in the observation-event among the studies used. To be of any use theconsistency among studies to be compared and contrasted should exist between either the observers themselves (i.e., person), the circumstances under which observations occurred and were made (i.e., occasion), or the devices that were used to do so (i.e., instrument).

For the present paper, the similarity was among the strengths of the studies and related to efforts that enhance "inter-observational agreement," which improves "reliability" and "accuracy" that is conducive to making research replicable (Martella, 2013). It was because of the presence of such thematic consistency among the strengths of the studies that the author felt comparison and contrast was possible. Whether according to person, to the occasion, or the instrument, the similarity served as a lens through which to conduct this analysis to determine the extent to which there exists inter-observational agreement and have confidence in the conclusions drawn to answer the present paper's research question.

\section{Differences in Weakness Due to Threats and Bias}

Despite the studies sharing similarities regarding methodological strengths as noted, the same may not be said of their weaknesses. No research is conducted without the potential for undesirable threats. Threats introduce weaknesses in research efforts and come in many forms. The forms that are both pertinent and prominent in the studies analyzed in the present paper will be discussed in the following paragraphs.

Resentful demoralization of the control group is a threat that could weaken a study resulting in differences between groups. In this case, differences may be exaggerated due to a lack of effort on the part of the controls, which could have been the case in Tao \& Shi (2018) especially if the students not chosen for enrichment programs found out somehow. Also, history 
may interfere and result in differences found due to some other variable between measurements to which participants exposed.

Another troubling threat or potential bias concerning Tao \& Shi's (2018) study includes the manner in which the sample for enrichment was picked as well as the different initial and final tests differing. Such differential selection in assignment or testing of groups could have occurred. The basis for claiming the potential for it to occur is due to admitted failure to consider attending in the sample selection and testing processes.

Furthermore, a threat to external validity, or the ability or extent to which the results may be generalized to the population, was likely an issue in Tao \& Shi (2018). I contend that the lack of consideration to attention in the sample creates a question in research consumers' minds as to whether all gifted children in enriched programs could benefit. Because attention was overlooked, failure to view it as that which possibly allowed for the gains from the gifted enrichment program precluded the researchers from considering a very plausible explanation for the findings. Although having proper attention may not be sufficient by itself for gifted students to reap the rewards from enrichment programs, I claim that it may be necessary to have. In the case of findings obtained if one were to conduct a thought experiment in which there were students in the enrichment program who were gifted yet found not to possess great attention skills, for example, gifted students with ADHD, they would be considered twice-exceptional or 2e. I argue that if $2 e$ students were chosen for enrichment, then a dramatic and significant reduction in the number of student gains from the program could be observed if any gains occurred all.

Differences in the combined experimental group could be explained by many things including participants attention, or interest, which threatens external validity or population 
validity. Besides, Foley-Nicpon et al. summer program's youth attendance could have been due to differences in students interest in and suggesting themselves to go in the first place. That is to say; there may have been an intrinsic "motivational" factor that could explain the findings (i.e., intervention worked for gifted student attendees because they were interested and motivated in participating in the summer program). Thus, the motivation or interest could be necessary for the benefits from the intervention to be effective. In this respect, an interaction of personological variables with the intervention was responsible (Martella, 2013).

Ecological verification of the independent variable refers to the extent to which implementations of the independent variable can be reproduced precisely in the real world (Martella, 2013). An example of this type of threat affecting the studies in the paper would be the Hawthorne effect if the interventions involved increased attention paid to participants (and most likely would). It would be difficult to determine whether the added attention or the intervention delivered was responsible for the observed results. Furthermore, without much attention being paid to them in the outside world, the results would not be obtained or reproducible.

Multiple treatments may have also threatened the dependent measures because participants were exposed to additional variables in the case of the gifted students who took part over the 2-week summer program. Novelty and disruption effects may also have posed a threat if it were determined that in Foley-Nicpon et al. not only was the attention of students required to benefit from the intervention video modeling, but the novelty and disruption of the experiment itself added to the effects being observed. In the case of the 2-week summer program, the novelty and disruption would be part of the additional attention given to participants, which contributes to the Hawthorne effect (Martella, 2013).

Experimenter effects, Interaction of time of measurement and treatment effects 
Moreover, Measurement of the dependent variable all could have affected the findings of the studies limiting their generalizability. For instance, in Foley-Nicpon et al., instead of looking at the quality of friendships, what if we measured the number of friendships, or amount of friendships maintained, or the stress associated with maintaining and making friends? It is entirely possible the intervention may not be seen as useful considering these as dependent measures.

\section{Conclusion}

In response to the primary research question, for gifted individuals with a disability (i.e., "twice-exceptional" or "2e") the answer is yes, effective interventions and strategies do exist that can improve domain-specific (i.e., social, emotional, or academic) outcomes. Based on the evidence, it may also be concluded that not only do directly effective interventions or strategies that can improve specific domains, but the effects of a domain-specific intervention can carry over into another domain resulting in indirect effects.

Any potentially gifted student is likely to satisfy requirements to qualify as having a learning disability according to some measure (Lovett, 2011). If it is true that all gifted students have some form of disability, then it could be inferred that giftedness results from an imbalance between the two domains according to which one possesses the gifts and disabilities. The domains causing the disabilities and gifts to manifest can be viewed as a consequence of, or attributed to, the dynamism between the two. Furthermore, the relation between gifts and disabilities appears to be such that individuals possessing both seemingly pay a hefty price for their particular level of giftedness by tendering a corresponding amount of disability currency.

A corollary is that the disabled must also have gifts, just like the character played by Dustin Hoffman in the movie Rain Man. A claim is not being made claiming people do not exist 
who may be considered intellectually "average." Nonetheless, I am suggesting that the average person either has prominent gifts overshadowing their disabilities or vice versa, which results in an overall blunting or net neutralization effect. In other words, it is not that average people lack gifts and disabilities; people who appear average do possess both gifts and disabilities, but because they are quantitatively equal but qualitatively opposing, either one can interfere with the expression of the other.

Since it has been explained how the gifted may possess talents in one domain that exceed the disabilities that would be demonstrated in another domain according to Lovett (2011), average individuals can be considered to have both gifts and disabilities that neutralize one another. For those who are designated disabled, they are thought to suffer from deficits that outweigh or overshadow their gifts by way of commutativity of conjunctions (i.e., if $\mathrm{g}$ and $\mathrm{d}$ then $\mathrm{d}$ and $\mathrm{g}$ is logically equivalent) (Barker-Plummer, Barwise, Etchemendy, \& Barwise, 2011). Everyone could be classified from an alternative theoretical framework within which there exists a gift/disability domain dichotomy that can be used to explain all observed manifestations along the continuum from gifted, through average, and to disabled. Future research will consider the use of this gift/disability domain dichotomy as a theoretical framework in an attempt to explain the entire gamut of unique manifestations of twice-exceptionality. 


\section{References}

Antshel, K. M., Faraone, S. V., Stallone, K., Nave, A., Kaufmann, F. A., Doyle, A.,. . . Biederman, J. (2007). Is attention deficit hyperactivity disorder a valid diagnosis in the presence of high IQ? Results from the MGH longitudinal family studies of ADHD.Journal of Child Psychology and Psychiatry, 48(7), 687-694. 10.1111/j.14697610.2007.01735.xLink

Barker-Plummer, D., Barwise, J., Etchemendy, J., \& Barwise, J. (2011). Language, proof, and logic.

Fineout-Overholt, E. \& Johnston, L. (2005), Teaching EBP: asking searchable, answerable clinical questions. Worldviews on Evidence-Based Nursing, 2, 157-160. doi: http://dx.doi.org/10.1111/j.1741-6787.2005.00032.x

Foley-Nicpon, M., Assouline, S. G., Kivlighan, D. M., Fosenburg, S., Cederberg, C., \& Nanji, M. (2017). The impact of a social and talent development intervention for high ability youth with social skill deficits. High Ability Studies., published online first. https://doi.org/10.1080/13598139.2017.1298997

Kirk, S. A., \& Bateman, B. (1962). Diagnosis and Remediation of Learning Disabilities. Exceptional Children, 29(2), 73-78. https://doi.org/10.1177/001440296202900204

Lovett, B. J. (2011). On the Diagnosis of Learning Disabilities in Gifted Students: Reply to Assouline et al. (2010). Gifted Child Quarterly, 55(2), 149-151. doi:10.1177/0016986210396435

Martella, R. C. (2013). Understanding and interpreting educational research [Kindle 6 Version] (1st ed.). 
Pisacco, N. M. T., Sperafico, Y. L. S., Enricone, J. R. B., Guimarães, L. S. P., Rohde, L. A., \& Dorneles, B. V. (2018). Metacognitive interventions in text production and working memory in students with ADHD. Psicologia: Reflexão e Crítica, 31(1), 5.

Reis, S. M., Baum, S. M., \& Burke, E. (2014). An Operational Definition of Twice-Exceptional Learners: Implications and Applications. The Gifted Child Quarterly, 58

Subotnik, R. F., Olszewski-Kubilius, P., \& Worrell, F. C. (2011). Rethinking Giftedness and Gifted Education: A Proposed Direction Forward Based on Psychological Science. Psychological Science in the Public Interest: A Journal of the American Psychological Society, 12(1), 3-54. https://doi.org/10.1177/1529100611418056

Summit Center (n.d.) What is Twice-Exceptional (2e)? Retrieved September 15, 2018, from https://summitcenter.us/about/what-is-twice-exceptional-2e/

Tao, T., \& Shi, J. (2018). Enriched education promotes the attentional performance of intellectually gifted children. High Ability Studies, 1-13.

University of Canberra. (2018, September 25). UC Library Guides: Evidence-Based Practice in Health: Types of Clinical Question. Retrieved from https://canberra.libguides.com/c.php?g=599346\&p=4149723

Wright, J. (2010). RTI Wire: Your Site for RTI Resources. Retrieved from http://www.jimwrightonline.com/php/rti/rti_wire.php 


\section{Table 1.}

\begin{tabular}{|c|c|}
\hline Citation & $\begin{array}{l}\text { Antshel, K. M., Faraone, S. V., Stallone, K., Nave, A., Kaufmann, F. A., Doyle, A., ... } \\
\text { Biederman, J. (2007). Is attention deficit hyperactivity disorder a valid diagnosis in the } \\
\text { presence of high IQ? Results from the MGH longitudinal family studies of ADHD. } \\
\text { Journal of Child Psychology and Psychiatry, 48(7), 687-694. 10.1111/j.1469- } \\
\text { 7610.2007.01735.XLink }\end{array}$ \\
\hline Purpose & $\begin{array}{l}\text { This study aimed to assess the validity of diagnosing attention deficit/ hyperactivity } \\
\text { disorder (ADHD) in high IQ children and to further characterize the clinical features } \\
\text { associated with their ADHD. }\end{array}$ \\
\hline $\begin{array}{l}\text { Research } \\
\text { Questions/Hypotheses }\end{array}$ & $\begin{array}{l}\text { A priori research hypotheses were that 1) Gifted/ high IQ children with ADHD more } \\
\text { impaired than non-ADHD IQ-matched children; 2) Clinical correlates in the children with } \\
\text { ADHD and giftedness/ high IQ mirror those reported in the average IQ ADHD } \\
\text { population; 3) Gifted/ high IQ children with ADHD would have a higher rate of familial } \\
\text { ADHD in first-degree relatives than IQ-matched ones without ADHD 4) rate of familial } \\
\text { ADHD in first-degree relatives in High IQ sample comparable to our sample of children } \\
\text { with ADHD who have an average IQ. }\end{array}$ \\
\hline Intervention & Diagnostic Validity \\
\hline $\begin{array}{l}\text { Research } \\
\text { Design } \\
\text { \& Sample }\end{array}$ & $\begin{array}{l}\text { Case-Control Study in which researchers identified } 92 \text { children with high IQ who did not } \\
\text { have ADHD and } 49 \text { children with high IQ that met diagnostic criteria for ADHD who had } \\
\text { participated in the Massachusetts General Hospital Longitudinal Family Studies of } \\
\text { ADHD. }\end{array}$ \\
\hline Measure(s) & $\begin{array}{l}\text { Psychiatric assessments of probands, siblings/ parents and controls relied on the Schedule } \\
\text { for Affective Disorders and Schizophrenia, Epidemiologic version (K-SADS-E; } \\
\text { Orvaschel \& Puig-Antich, 1987). ADHD diagnoses were based on independent interviews } \\
\text { with the mothers and direct interviews of children older than } 12 \text { years. When the } \\
\text { information from mother and child was discrepant, the most severe report was utilized. } \\
\text { For example, when one reporter endorsed a symptom and the other did not, we counted } \\
\text { the symptom as present. For every ADHD diagnosis, information was also gathered } \\
\text { regarding the ages at onset and offset of symptoms, number of episodes and treatment } \\
\text { history. }\end{array}$ \\
\hline Results & $\begin{array}{l}\text { Of the participants with ADHD and a high IQ, the majority (n } 1 / 435) \text { met criteria for the } \\
\text { Combined subtype. Relative to control participants, children with ADHD and high IQ had } \\
\text { a higher prevalence rate of familial ADHD in first-degree relatives, repeated grades more } \\
\text { often, had a more mediocre performance on the WISC-III Block Design, had more } \\
\text { comorbid psychopathology and had more functional impairments across some domains. }\end{array}$ \\
\hline Strengths & $\begin{array}{l}\text { Strength in the methods: operationalized high IQ; establishes reasonable criterion; control } \\
\text { group used; could have also investigated either average IQ/ADHD or high IQ/ADHD for } \\
\text { comparison. }\end{array}$ \\
\hline Weaknesses & $\begin{array}{l}\text { Weakness was that they operationalized IQ to be high at } 120 \text {; some would disagree that } \\
120 \text { is not high enough. Moreover, that, findings from the study showing ADHD being } \\
\text { applicable to } 120 \text { IQ population may not be for individuals with IQ higher than } 120 \text {. so } \\
\text { for say } 125 \text { or } 130 \text {. In other words, high is vague and relatively speaking why } 120 \text { was } \\
\text { chosen for IQ moves unclear. Convenience? Also, only controls found were half as many } \\
\text { as in the experimental group. }\end{array}$ \\
\hline
\end{tabular}


Table 2.

\begin{tabular}{|c|c|}
\hline Citation & $\begin{array}{l}\text { Tao, T., \& Shi, J. (2018). Enriched education promotes the attentional performance of } \\
\text { intellectually gifted children. High Ability Studies, 1-13. } \\
\text { Is an enriched education program effective for intellectually gifted children's } \\
\text { attention? }\end{array}$ \\
\hline Purpose & $\begin{array}{l}\text { The present study focused on the effect of enriched education on intellectually gifted } \\
\text { children's attention. }\end{array}$ \\
\hline $\begin{array}{l}\text { Research } \\
\text { Questions/Hypotheses }\end{array}$ & $\begin{array}{l}\text { hypotheses were 1) Gifted/ high IQ children with ADHD would have higher levels of } \\
\text { functional impairment relative to IQ-matched children who do not have ADHD; 2) } \\
\text { Clinical correlates in the children with ADHD and giftedness/ high IQ would mirror } \\
\text { those reported in the average IQ ADHD population; 3) Gifted/ high IQ children with } \\
\text { ADHD would have a higher rate of familial ADHD in first-degree relatives than IQ- } \\
\text { matched children who do not have ADHD; and 4) The rate of familial ADHD in first- } \\
\text { degree relatives in the sample of children with a high IQ would be comparable to the } \\
\text { sample of children with ADHD who have an average IQ. }\end{array}$ \\
\hline Intervention & Enriched Education \\
\hline $\begin{array}{l}\text { Research } \\
\text { Design } \\
\& \text { Sample }\end{array}$ & $\begin{array}{l}\text { Participants selected were intellectually gifted children aged } 7-12 \text { years Children in } \\
\text { the gifted-education group were recruited from an experimental class that was } \\
\text { specifically designed to offer enriched education for gifted children nationwide. The } \\
\text { design of the study involved } 7-12 \text {-year-old children completing seven tests of } \\
\text { attention (alertness, focused attention, divided attention, attentional switching, } \\
\text { sustained attention, spatial attention, and supervisory attention) to investigate the } \\
\text { differences among intellectually gifted children under different educational } \\
\text { environments }\end{array}$ \\
\hline Measure(s) & $\begin{array}{l}\text { Psychiatric assessments of probands, siblings/ parents and controls relied on the } \\
\text { Schedule for Affective Disorders and Schizophrenia, Epidemiologic version (K- } \\
\text { SADS-E; Orvaschel \& Puig-Antich, 1987). ADHD diagnoses were based on } \\
\text { independent interviews with the mothers and direct interviews of children older than } \\
12 \text { years. When the information from mother and child was discrepant, the most severe } \\
\text { report was utilized. For example, when one reporter endorsed a symptom and the other } \\
\text { did not, we counted the symptom as present. For every ADHD diagnosis, information } \\
\text { was also gathered regarding the ages at onset and offset of symptoms, number of } \\
\text { episodes and treatment history. }\end{array}$ \\
\hline Results & $\begin{array}{l}\text { The results showed that intellectually gifted children who received enriched education } \\
\text { had better attentional performance than did intellectually gifted children who received } \\
\text { the standard education. The main differences between intellectually gifted children } \\
\text { who received enriched education and intellectually gifted children who received a } \\
\text { standard education were found in accuracy. In particular, when compared to } \\
\text { intellectually gifted children who received a standard education, the three groups who } \\
\text { received an enriched education had greater accuracies on the sustained attention task. } \\
\text { Ultimately, the more years of enriched education that students received (i.e., the higher } \\
\text { their age), the higher was their accuracy on the attention tasks in comparison to the } \\
\text { intellectually gifted children who were receiving a standard education. }\end{array}$ \\
\hline Strengths & $\begin{array}{l}\text { Gifted education program underwent multiple verified procedures, which increases } \\
\text { reliability in the identification of giftedness present. Using only a particular portion or } \\
\text { section of a test minimized the effect of waning attention on performance }\end{array}$ \\
\hline Weaknesses & $\begin{array}{l}\text { The process by which the sample was selected for Gifted Enrichment Education was } \\
\text { inconsistent. The domains assessed were not identical in the test and retest. Reliance } \\
\text { on potential performance level may allow false identification of kids as gifted. Using } \\
\text { part/section of a test may result in overestimating intelligence and allow for } \\
\text { participants to be included among the group of gifted when they should not be. } \\
\text { Attention had not been considered in the selection process, but attentional capacity } \\
\text { varies even among gifted. Attentional capacity itself may play a role in benefit from }\end{array}$ \\
\hline
\end{tabular}


enrichment program. A direct correlation, if it exists, would predict greater attention yield more significant benefit. 


\section{Table 3.}

\begin{tabular}{|c|c|}
\hline Citation & $\begin{array}{l}\text { Pisacco, N. M. T., Sperafico, Y. L. S., Enricone, J. R. B., Guimarães, L. S. P., Rohde, L. } \\
\text { A., \& Dorneles, B. V. (2018). Metacognitive interventions in text production and working } \\
\text { memory in students with ADHD. Psicologia: Reflexão e Crítica, 31(1), 5. The } \\
\text { investigation }\end{array}$ \\
\hline Purpose & $\begin{array}{l}\text { This study compared the effects of two metacognitive interventions on writing, working } \\
\text { memory (WM), and behavioral symptoms of students with attention-deficit/ hyperactivity } \\
\text { disorder (ADHD). }\end{array}$ \\
\hline $\begin{array}{l}\text { Research } \\
\text { Questions/Hypotheses }\end{array}$ & $\begin{array}{l}\text { What interventions can contribute to improving the writing performance of students with } \\
\text { ADHD? The research hypothesis is that greater improvement regarding specific text } \\
\text { production skills and behavioral symptoms in students with ADHD should occur when } \\
\text { using a combined intervention rather than using a WM intervention alone. }\end{array}$ \\
\hline Intervention & $\begin{array}{l}\text { Self-Regulation Strategies as Metacognitive interventions. One intervention combined } \\
\text { WM training with specific text production skills, while the other focused only on WM. }\end{array}$ \\
\hline $\begin{array}{l}\text { Research } \\
\text { Design } \\
\& \text { Sample }\end{array}$ & $\begin{array}{l}\text { Experimental comparative intervention research; analyzed measures obtained before, at } \\
\text { the end, and } 3 \text { months afterwards; randomized sample from } 1800 \text { kids in } 2 \text { similar } \\
\text { elementary public schools forming combined intervention group (IG-Combined) and the } \\
\text { WM intervention group (IG-WM; selection, evaluation, and intervention done at schools; } \\
47 \text { students from the fifth to ninth grades; mean age }=13.07 \text { years (SD = 1.78). Inclusion - } \\
\text { Portuguese language, estimated IQ equal to or higher than 80, according to WISC-IV and } \\
\text { ADHD diagnosis, according to the DSM-IV criteria (American Psychiatric Association, } \\
\text { 2002). Exclusion criteria - intellectual, sensory, or motor disabilities; autistic spectrum } \\
\text { disorder, bipolar mood disorder, and depression in comorbidity with ADHD; and } \\
\text { alphabetic or spelling phase of writing. }\end{array}$ \\
\hline Measure(s) & $\begin{array}{l}\text { Evaluation was done by an external multidisciplinary team with experience in the } \\
\text { evaluation of children and adolescents with mental disorders. The Portuguese version of } \\
\text { the SNAP-IV was applied to teachers by education experts to identify probable cases of } \\
\text { ADHD among students. A questionnaire formulated according to the DSM-IV criteria for } \\
\text { ADHD diagnosis (American Psychiatric Association, 2002) features } 18 \text { symptoms (nine } \\
\text { related to inattentiveness and nine associated with hyperactivity/ impulsivity) arranged on } \\
\text { a Likert scale. SNAP-IV was done before and soon after. }\end{array}$ \\
\hline Results & $\begin{array}{l}\text { The results suggest that both interventions contributed to improving behavior and school } \\
\text { performance, whereas only the combined intervention increased the overall quality of } \\
\text { narrative text, organization of paragraphs, and denouement }\end{array}$ \\
\hline Strengths & A multidisciplinary team clinically diagnosed the disorder according to DSM-IV criteria. \\
\hline Weaknesses & $\begin{array}{l}\text { Weakness was that they excluded people with comorbidities like ADHD, because of } \\
\text { ADHD symptoms; no comparison with either a non-intervention control group or an } \\
\text { intervention focused only on text production }\end{array}$ \\
\hline
\end{tabular}




\section{Table 4.}

\begin{tabular}{|c|c|}
\hline Citation & $\begin{array}{l}\text { Foley-Nicpon, M., Assouline, S. G., Kivlighan, D. M., Fosenburg, S., Cederberg, C., \& } \\
\text { Nanji, M. (2017). The impact of a social and talent development intervention for high } \\
\text { ability youth with social skill deficits. High Ability Studies., published online first. } \\
\text { https://doi.org/10.1080/13598139.2017.1298997 }\end{array}$ \\
\hline Purpose & $\begin{array}{l}\text { To determine the effectiveness of social and talent development interventions in high } \\
\text { ability youth with self-reported social difficulties }\end{array}$ \\
\hline $\begin{array}{l}\text { Research } \\
\text { Questions/Hypotheses }\end{array}$ & $\begin{array}{l}\text { Expected greater improvement regarding specific text production skills and behavioral } \\
\text { symptoms in students with ADHD when using a combined intervention rather than talent } \\
\text { only; Asked (1) In comparison to students receiving only the talent development } \\
\text { intervention, do students' self-reported friendship qualities (companionship, conflict, } \\
\text { help, security, and closeness) change following a two-week talent development and video } \\
\text { modeling intervention? Hypothesized significant differences between the social skills } \\
\text { intervention and comparison groups on changes in participants' friendship quality in the } \\
\text { domains of companionship, conflict, help, security, and closeness. (2) Do students' } \\
\text { achievement goal orientation (i.e., mastery, performance approach, or performance avoid) } \\
\text { and academic efficacy influence changes in their friendship qualities following a two- } \\
\text { week talent development and video modeling intervention? }\end{array}$ \\
\hline Intervention & Social and Talent Development Intervention \\
\hline $\begin{array}{l}\text { Research } \\
\text { Design } \\
\& \text { Sample }\end{array}$ & $\begin{array}{l}28 \text { students of whom } 12 \text { had a coexisting disability, participated in social skills and talent } \\
\text { development intervention during a two-week summer enrichment program. Randomized } \\
\text { into the combined intervention group (IG-Combined) and the WM intervention group } \\
\text { (IG-WM). }\end{array}$ \\
\hline Measure(s) & $\begin{array}{l}\text { Patterns of Adaptive Learning Scales (PALS; Midgley et al., 2000) to understand the } \\
\text { relationship between the learning environment, motivation, affect, and behavior. } 14 \\
\text { items, three subtests assess personal achievement goal orientations: Mastery approach to } \\
\text { developing competence - adaptive pattern of learning, performance approach to } \\
\text { demonstrate competence - both adaptive and maladaptive pattern of learning, and } \\
\text { performance avoidance to avoid demonstrating incompetence - a maladaptive pattern of } \\
\text { learning. 23-item Friendship Qualities Scale (FQS; Bukowski, Hoza, \& Boivin, 1994) } \\
\text { self-report; scale from 1-5, scores as means within Companionship (spending time with } \\
\text { friends), Conflict (fights with friends), Help (assistance one can get from friends), } \\
\text { Security (reliable, trustworthy friends who make up after conflict), and Closeness } \\
\text { (appraisal of friendship bonds). Scores for Conflict negatively correlated with scores } \\
\text { from all other scales. }\end{array}$ \\
\hline Results & $\begin{array}{l}\text { Compared to high ability youth not in the social skills intervention }(n=9) \text {, participants } \\
\text { reported positive changes in friendship qualities (help), indicating treatment effect. }\end{array}$ \\
\hline Strengths & $\begin{array}{l}\text { The decision to research an established 2-week long summer program, evaluating before, } \\
\text { at the end of, and three months following the intervention that occurred, and using } \\
\text { validated instruments/measurement devices PALS \& FQS. }\end{array}$ \\
\hline Weaknesses & $\begin{array}{l}\text { Because the evaluations before, in the end, and three months after ending, there may be } \\
\text { confounding variables that could explain the maintenance of the observed results. }\end{array}$ \\
\hline
\end{tabular}


